\title{
Como trabalhar teatro na sala de aula?
}

\author{
Camila Aschermann ${ }^{1}$ \\ Eder Sumariva Rodrigues ${ }^{2}$
}

A abordagem deste relato de experiência é realizar uma reflexão dos procedimentos metodológicos e dos resultados adquiridos durante o processo de estágio V em 2005/2 e apresentar uma proposta uma nova forma para trabalhar o teatro na rede pública de ensino.

"Nunca senti isso. Minha perna ficou mole, minhas mãos tremiam, meu corpo estava quente, minha visão embaçada e, por fim, meu pensamento corria muito rápido. Acho que foi o momento mais feliz da minha vida"

\footnotetext{
${ }^{1}$ Graduada em Artes Cênicas pela Universidade do Estado de Santa Catarina.

2 Atualmente mestrando do Programa de Pós-Graduação em Teatro pela Universidade do Estado de Santa Catarina. Foi bolsista $\mathrm{PIBIC/CNPq}$ no projeto de pesquisa "O Teatro de Grupo e a Construção dos Modelos de Trabalho do Ator"
} 
As oficinas de teatro realizadas na Escola Estadual Básica Silveira de Souza durante o ano de 2005 trouxeram significativos resultados metodológicos durante o processo de construção do espetáculo Aquele que diz sim, Aquele que diz não de Bertolt Brecht (1898-1956). Estas oficinas tinham por objetivo realizar o último estágio da grade curricular do curso de Artes Cênicas da UDESC. Este estágio foi realizado com 11 crianças $^{1}$ que tinham entre 8 e 11 anos de idade que estudavam na terceira e quarta série da referida escola. Buscando um processo contínuo $^{2}$ e permanente com a intenção de firmar laços afetivos e de saberes com a comunidade local e escolar através da arte, o processo foi permeado pela troca de experiências entre educandos e mediadores. Neste processo de construção da encenação, optamos em realizar a mediação com o objetivo de intermediar o entendimento do texto do dramaturgo alemão Brecht com a realização da cena, contextualizada com situações vivenciadas ou presenciadas pelos educandos. Esta mediação entre texto e cena foi fundamental para o desenvolvimento do trabalho, pois as personagens foram construídas com base nas discussões que se faziam ao final de cada sessão da oficina. Escutar a releitura

\footnotetext{
${ }^{1}$ Participaram deste estágio os seguintes alunos: Amado, Paloma, Bruna, Vitória, Letícia, Florência, Yuseff, Guilherme, Gilmar, Renan e Ana Caroline.

2 O estágio IV também foi realizado na mesma unidade educativa. Nesta etapa foram desenvolvidas apenas oficinas sem intenção de montagem. $O$ regresso dos alunos para o segundo semestre de 2005 foi integral.
} 
dos educandos e suas experiências proporcionou construir um universo de diálogo, respeito e confiança no qual todos podiam expor suas idéias e opiniões e consequentemente, nós, estagiários, deveríamos trabalhar com as informações fornecidas pelos educandos e colocá-las em cena. A criação deste harmonioso ambiente possibilitou a criação de um espetáculo coletivo e não uma idéia imposta e concebida pelos estagiários. Sendo assim, a noção de mediação parece ser mais bem apropriada para os profissionais de teatro que se dedicam a trabalhar em escola ou comunidade em projetos extra-classe ou extra-curricular.

Neste sentido, o estágio foi baseado com as seguintes premissas: inserção da realidade dos participantes na cena, jogos e improvisos teatrais; pesquisa da dramaturgia cênica e interpretação de ator baseada nas vivências das histórias dos alunos-atores; valorização do conhecimento que o educando traz para a sala de aula na construção coletiva do universo do grupo.

Todos os encontros foram realizados aos sábados à tarde na sede da escola e tinham uma estrutura base para o desenvolvimento da oficina: aquecimento, improvisação de cenas e finalizamos com um bate-papo com os integrantes do projeto. Esta estrutura do plano de aula teve por objetivo dois pontos principais: deixar claro aos participantes como funcionariam as oficinas e estabelecer uma seqüência nos debates, pois somente a partir 
desse diálogo é que poderíamos aprofundar a cena improvisada por eles. Cabe deixar claro que ao final do processo, com a montagem do espetáculo, esta estrutura foi alterada passando a vigorar somente o aquecimento e ensaio da peça.

$\mathrm{Na}$ medida do possível, durante este processo de estágio foi transmitido aos educandos, ressaltando a importância da reflexão sobre a realidade social que estão inseridos. 0 que se pretendeu proporcionar não são somente homens como se fossem peças anatômicas, mas o seu pensamento referido à realidade, análise crítica de uma dimensão que possibilita aos indivíduos uma nova postura crítica, em face. A captação e a compreensão da realidade se refazem, ganhando um nível que até então não tinham, a partir da peça didática Aquele que sim, Aquele que diz não na qual coloca os participantes em confronto com situações que necessitam de uma posição/visão de mundo.

\section{Dramaturgia X Espaço1: uma possível solução}

Em Aquele que diz sim, Aquele que diz não, o eixo central da dramaturgia calca-se na tradição da travessia do vale. $\mathrm{Na}$ primeira versão apresentada por Brecht, o menino adoece e não pode continuar a travessia para

${ }^{1}$ Aula realizada em 22 de novembro de 2005. 
busca de remédio para sua mãe. Seguindo a tradição local, o professor e os três estudantes teriam que abandoná-lo na montanha, “mas é justo que se pergunte àquele que ficou doente se se deve voltar por sua causa. E o costume exige que aquele que ficou doente responda: vocês não devem voltar”. Respondendo conforme a necessidade, o menino diz que eles não devem voltar para a cidade, pede que seu corpo seja jogado no abismo: "O professor Vocês decidiram continuar e deixá-lo aqui. É fácil decidir o seu destino. Mas difícil executálo. Estão prontos para jogá-lo no vale?”

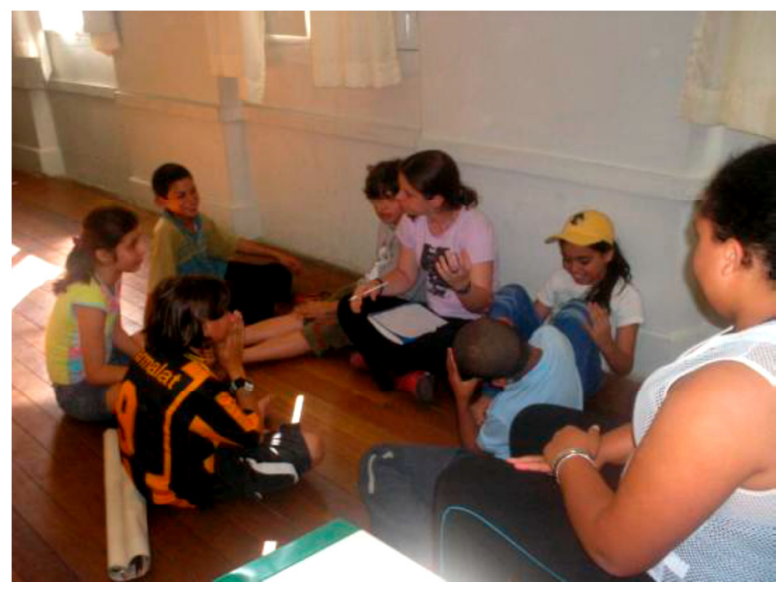

Na segunda parte, o menino não responde conforme o costume, afirma que é preciso um novo grande costume, o de refletir diante de cada nova situação. Com a decisão do menino em voltar para a cidade, o professor e os três estudantes acatam sua posição/resposta e 
retornam. A partir da contação $^{1}$ da fábula pelos estagiários para os alunos-atores 0 processo começa ter um caráter diferenciado, o enfoque passa para a construção do espetáculo. Intercalando a importância do processo, a contextualização do texto, a ludicidade das crianças, a criatividade coletiva, o processo colaborativo, com a necessidade da construção do conhecimento da história e entendimento de técnicas teatrais realizam-se improvisações sobre o eixo principal da dramaturgia a ser trabalhada (nesse caso a quebra de tradição é ponto fundamental de trabalho).

É fundamental a realização de discussão sobre o texto e é imprescindível que os mediadores interfiram diretamente no debate, fazendo perguntas chaves e trazendo temas atuais permeando com a realidade dos participantes. Toda dramaturgia possui suas ramificações e no caso de Aquele que diz sim, Aquele que diz não há várias vertentes que foram trabalhadas: a pobreza da cidade, transmissão de doenças e quem seria essas personagens na comunidade em que vivem.

0 questionamento sobre a quebra de tradição transpondo para a realidade de cada um dos participantes é essencial para que haja entendimento do tema central que estávamos trabalhando. Indagamos sobre as quebras de costumes, e até que ponto elas eram benéficas

\footnotetext{
${ }^{1}$ No início das oficinas foram realizados alguns jogos de improvisação. Posteriormente a fábula foi contada aos educandos na qual foram construindo as cenas. Por último a vinda do texto.
} 
e porque algumas não eram aceitas. Para tanto, estas situações devem ser contextualizadas nos ambientes que o texto dramaticamente propõe: escola, família, comunidade.
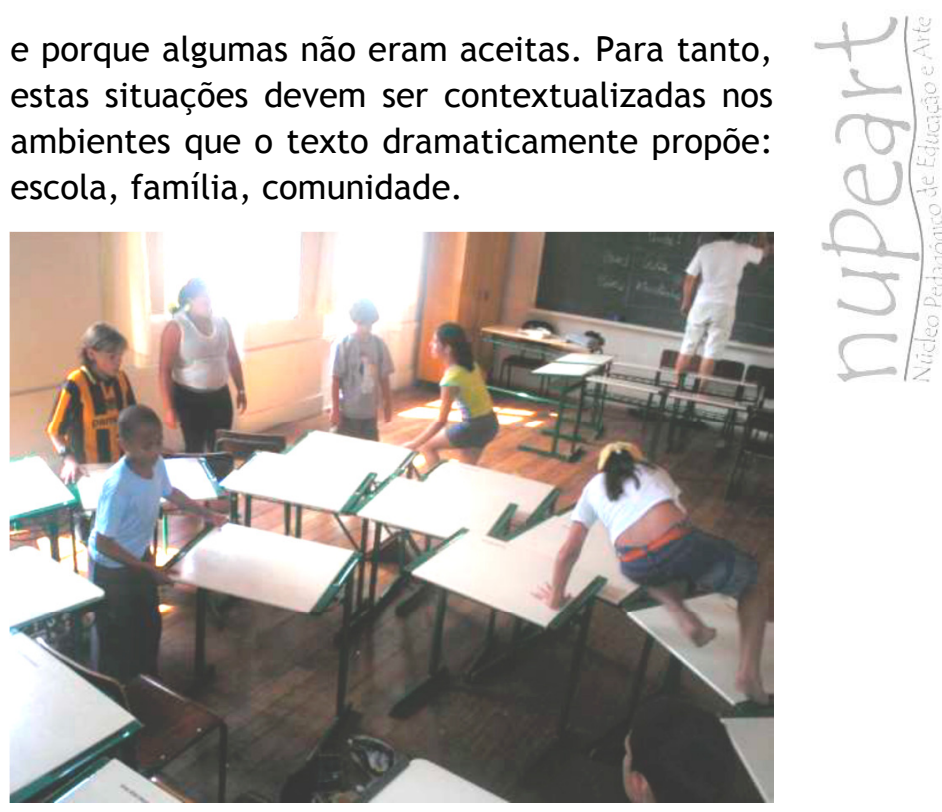

Desencadeou numa das discussões com o grupo a temática da educação, vertente presente na dramaturgia do texto, que formula a idéia de ser um professor perfeito. Indagados por essa vertente e os educandos se opuseram a idéia do professor exemplar. Expuseram situações de sala de aula: professores autoritários, que xingam e batem em alunos. Essas situações apareceram espontaneamente dos alunos-atores justamente por ser algo que não desejam que aconteça, assim a personagem do professor é vista como sob um novo ângulo, e que foi reelaborada para cena. Inserida no contexto da dramaturgia/espetáculo, a figura do professor que está no texto de Brecht, àquele que educa, que detém a sabedoria, foi transformada em general, e os estudantes em soldados. 
Partindo dessa experiência proporcionada pelos próprios participantes, os mediadores devem tratar essas personagens conforme seu contexto. A forma de falar e a codificação necessária para designar tais papéis, e nesse caso os soldados eram tratados por números, servindo como base de preparação para composição da personagem, aproximando o imaginário e contexto com a realização da cena.

o trabalho dramatúrgico deve ser reforçado todas as aulas a fim de fixar a fábula como um todo, perguntando aos alunos-atores todas as etapas correntes do texto. Em Aquele que diz sim Aquele que diz não, a estrutura dramatúrgica divide-se numa sequiência de acontecimentos e da mudança espacial. Nesta etapa utilizamos os recursos desenvolvidos por Viola Spolin: 0 quê? Onde? Quem?.

Reforçando esses critérios em todas nas aulas ministradas, a fábula é apreendida facilmente pelos alunos-atores. Como mediadores, em nenhum momento, nos preocupamos em fazer com que os alunos-atores decorassem o texto, utilizamos o texto como pré-texto para a encenação.

Nossos encontros foram realizados dentro de uma sala de aula comum na qual sempre tínhamos que deixar mesas e cadeiras ao fundo amontoadas ao fundo da sala. Antes do início das atividades, vimos brincadeiras feitas pelos participantes em cima das carteiras amontoadas Vendo as crianças brincando com intimidade em cima das cadeiras e mesas, a primeira impressão 
era construir um palco, mas sugerimos que construíssem os dois ambientes que o texto de Brecht propunha: uma casa e uma montanha. Começou aí uma brilhante iniciativa, que acima de resolver um problema cenográfico, resignificou o convencional ambiente escolar.

Com o cenário já esboçado, propomos improvisação do texto juntamente com esta nova configuração espacial. Buscamos deixar claro desde o início que independente do personagem que cada aluno desempenhará na apresentação, eles deveriam experimentar todos os papéis que a dramaturgia fornecia. A experiência de possibilitar outros olhares sobre o espaço escolar e também com o material que até então era visto apenas como carteira e cadeira, mostrou-nos que às vezes os obstáculos podem ser transformados em solução, dependendo apenas da disponibilidade, da criatividade e da sensibilidade do grupo.

Esta iniciativa, que, acima de resolver um problema cenográfico desta encenação, gerando uma possibilidade do ambiente escolar, proporciona um novo olhar sobre o espaço de trabalho que, geralmente os professores de artes cênicas da rede pública enfrentam: escolas que não possuem estrutura adequada para ministrar aulas de teatro. Eis a cruel pergunta: como trabalhar teatro em uma sala de aula? Eis aqui uma possível possibilidade, um 
novo olhar sobre o fazer teatral na sala de aula ${ }^{1}$.

${ }^{1}$ Esta experiência foi repetida por Eder Sumariva Rodrigues nos anos de 2007 e 2008 no Instituto Estadual de Educação com as 6응 séries a partir dos textos de Luiz Fernando Veríssimo. O resultado demonstrou que os alunos absorvem com clareza a proposta de encenação teatral, pois rompem com o espaço convencional da rotina diária de estudos. 